\title{
"One For The Money"? \\ The impact of the "disk crisis" on "ordinary musicians" income: The case of French speaking Switzerland
}

\author{
Pierre Bataille ${ }^{1}$ et Marc Perrenoud ${ }^{2}$ \\ ${ }^{1}$ Université Grenoble-Alpes, LaRAC/LIVES \\ ${ }^{2}$ Université de Lausanne, LACCUS/LIVES
}

\begin{abstract}
The so called "disk-crisis" and the rise of music digitization and/or music piracy regularly make the headlines of general and specialized newspapers. The impacts of these metamorphoses on the more visible actors of the national musical industries are relatively well documented. Nevertheless, little is known about the impact of these changes on the musicians' incomes - especially the "ordinary" ones, who are located at the intermediary and the bottom stages of the professional hierarchy. This paper aims to contribute to better understanding the extent to which digitization reshaped the ways these little-known musicians make a living from music. To do so, we use longitudinal data collected from a sample of musicians active in the French-speaking part of Switzerland in the early 2010's. These data mainly consist of life calendar-data, with retrospective information on income sources for every year of the career - from the first gig played in public to 2013. Crossing sequence analysis and geometrical data analysis tools, we analyze whether or not digitization spurred a career reorientation to one of two major "poles" structuring the "ordinary musicians" professional space (the "artist" pole or the "craftsman" one). We show that changes are few. Nevertheless, we point out how social origin and gender impact these potential career reorientations. More broadly, our paper points to the need to analyze the social conditions of appropriability of technological innovations especially when it comes to symbolic goods.
\end{abstract}

Original reference: Bataille Pierre \& Marc Perrenoud (2021), "'One For The Money'? The impact of the "disk crisis" on "ordinary musicians" income: The case of French speaking Switzerland", Poetics, forthcomming.

\section{Introduction}

During the past two decades, the so called "disk crisis" and the rise of music digitization and music piracy have often made the headlines of general and specialized newspapers. The impact of these mutations on the more visible actors of the music industry (e.g., major companies and internationally famous artists) are relatively well documented (Williamson \& Cloonan, 2007). Less is known about the impact of these changes on the income of "ordinary musicians" (Perrenoud, 2007; Faulkner \& Becker, 2009), i.e. those who are neither rich nor famous and who make a living (or try to) by playing music. Based on a case study of active musicians in French-speaking Switzerland between 2012 and 2015, our article sheds light on the ways musicians at the intermediate and lower levels of the professional pyramid earn a living in the so-called digitization era.

The main research question that underpins this article can be summed up as follows: what social characteristics increase or reduce the impact of digitization on "ordinary musicians"' careers? We challenge the idea that digitization has radically changed the working routine of most musicians. We also analyze how digitization's impact differs by gender and educational background. By doing so, we point out how macrosocial relations shape "appropriability regimes" (Teece, 1986) when innovations come to symbolic/cultural goods markets (Bourdieu, 1985).

This article is divided into four sections. In the 
first part, we present a broad overview of the academic debate about the effects of digitization on little-known musicians' activities and careers. In the second part, we present our data and analytical strategy. The third section of this article presents our main results. We analyze the evolution of the musical revenue stream composition throughout Swiss ordinary musicians' careers - and focus on the variations regarding musicians' gender and education level. Finally, we discuss these results and show that the "disk crisis" had little impact on ordinary musicians' income. Nevertheless the "digitization era" seems to allow some individuals traditionally marginalized in the music industry (especially some women) to embrace a "creative career".

\section{Digitization: an opportunity for little-known musicians?}

\subsection{Digitization and its effects on mu- sical production organization: be- tween fragmentation and concentra- tion}

Literature on how digitization impacted national music industries is substantial, especially concerning North American or western European countries (Anderson, 2013; Marshall, 2013; Taylor, 2015; Witt, 2015). By "digitization," we mean the digitization of music diffusion due to the rise of the MP3 and the other digital musical formats that facilitated online sharing and selling since the mid-1990s. But we also mean the digitization of music production due to the rise of recording software that contributes to democratizing recording skills and opportunities. Available studies generally aim to show the extent to which digitization reshaped ways of making money with music, ways of working in the music sector, and the horizontal and vertical social divisions of musical work. These works are mainly focused on the musicians and companies in the popular music field, since the professional space of classical music has been less impacted by this "crisis" (Bourreau, Gensollen, Moreau, \& Waelbroeck, 2012) $)^{1}$. Most show that the metamorphoses in this sector since the 1980s have "jeopardized" the traditional musical business model. Such changes would have "[given] rise to more independent productions" (Pras, Guastavino, \& Lavoie, 2013, p. 612), "[broken] the music monopoly that has existed for a century" (Mc Leod, 2005, p. 530-531) and served to "increase the diversity of mu-

\footnotetext{
${ }^{1}$ Thus, in this article, even though we use the generic "musicians" appellation, our analysis mostly regards musicians involved in non-classical music - i.e. "popular music" musicians.
}

sic available to music fans" (Ibid.). The massive digitization of music production and distribution has led to an "accelerated vertical disintegration" of the musical business (Leyshon, 2009, p. 1327). It thus yielded "turbulent configurations" that are "nurturing cultural innovation" (Peterson \& Annand, 2004, p. 318) and drawing out the emergence of new (and smaller) actors in this area.

Some of the economic consequences of the downward turn in record sales are now relatively well identified. The growth of the live music sector, which became a major source of revenue during the last twenty years, is one of them (Behr, Brennan, \& Cloonan, 2016). Nevertheless, there is no clear consensus about the longterm consequences of these changes. Recent works on records companies show that the recomposition of the musical professional landscape since the 1990s followed diverse routes (Galuszka \& Wyrzykowska, 2016; Leyshon et al., 2005; Stahl \& Meier, 2012). The impact of digitization on record sales appears contradictory (Strachan, 2013). On the one hand, digitization has been ideally poised to "help less-known and new artists gain exposure" (Strachan, 2013, p. 2). Indeed, according to the "Long Tail" thesis (Anderson, 2006), "the democratization of music production, distribution, and consumption should shift the music industry's balance of power away from incumbents and in favor of these insurgent entrepreneurs" (Strachan, 2013, p. 2). By "creating place[s] where independent musicians could distribute music without the costly distribution systems required to get CDs to stores" (Arditi, 2014 , p. 408), digitization of music production and diffusion may have looked like a "very real possibility that most musicians can make a living from a small but loyal fan base, and completely bypass the bloated entertainment industry" (McLeod, p. 530). Empirical evidence of this first tendency is thin. But, looking at the physical-only record sales (and especially LP sales), it is possible to observe a "long tail effect" since 2000. The "niche artists" seem to have profited most from the "vinyl resurgence" and all the new processes of value creation through the "enhancement of customer experience" that went with this revival (Hracks \& Jansson, 2017). On the other hand, it seems clear that the global downfall of music sales had a "superstar effect". Those who sold more at the beginning of the 2000's consolidated and reinforced their dominance over the music market after digitization. At the same time, the number of musicians who were "intermediary sellers" diminished (Strachan, 2013). Some capitalized on new ways of broadcasting and selling music through platforms like iTunes or Spotify. These new digitized tools contributed to rebuilding stronger "walls" around the 
traditional dominant music business actors, after that digitization lowered the barriers to diffusing music for some musicians at first (Arditi, 2014). Furthermore, although it reinforces the monopoly of winner-take-all actors, digitization increased the level of competition among those who are little or not at all known (Klein et al. 2017) and provoked a drastic diminution of the "middle class of artists" (Strachan, 2013, p. 7).

To sum up, digitization did have two "opposite" consequences on the organization of musical work. On one hand, by breaking the monopoly of major companies, digitization may have led to the emergence of new actors and reduced wealth inequalities within this sector. On the other hand, digitization seems to have amplified the unevenness between leading institutions and actors in the musical field and others. Such tensions (creating new opportunities vs. strengthening inequalities) structure the debate about the effects of new technologies on musical production and labor. The analysis of the recorded music industry market structure evolution in France between 2000 and 2010 points this out with accuracy (Bourreau, Lestage, \& Moreau, 2017). At the beginning of the decade, the development of musical e-commerce provoked a decentralization of the record sales market - i.e. boosting sales for small music labels and more "niche" artists - and a relative decrease in the major companies' monopoly (Ibid.). In line with the "long tail" theory (Anderson, 2006), this trend supports the idea that "the future of the music business is to sell fewer units of a larger number of creations" (Bourreau, Gensollen, Moreau, \& Waelbroeck, 2012, p. 18). Nevertheless, after 2005, one can observe a re-centralization movement, which indicates that "larger firms in the industry have been initially slower to move online compared to small firms, but have eventually caught up with their small rivals" (Bourreau et al., 2017, p. 600). And the most recent studies (Guibert, Rebillard, \& Rochelandet, 2016; Arditi, 2014) show that e-commerce of digitalized cultural goods is mainly monopolized by big firms such as Google, Apple, etc.

Two major criticisms of the previous analyses can be addressed. First, these works mainly focus on musicians who create and sell their own music and the records sales companies. In doing so, they consider the impact of digitization on the musical economy and musical work organization in only two areas of the whole "musical network" production: the "reproduction" and "distribution" areas (Leyshon, 2001). Some sub-parts of this "musical network" have not been investigated under this "digitization" perspective. Thus, little is known about the concrete consequences of digitization and the so-called "disk crisis" on the incomes and prac- tices of the many musicians who stand on the middle and lower stages of the professional pyramid - i.e. the "ordinary musicians" (Perrenoud, 2007; Faulkner \& Becker, 2009), who represent the vast majority of people who play music for money but who rarely reach economic and/or critical consecration. Such musicians are similar to the "dance musicians" studied by Becker in the middle of the 20th century (1963). They make a living from musical work in various ways. Some of them teach music, some are composers, but most perform in different styles and situations, taking whatever comes their way. When they focus on the impact of digitization on musicians' income, existing works use mainly "music business-oriented" data, inducing substantial bias into the picture they seek to draw - for a deeper discussion of the limit of the Nielsen Soundscan database see Strachane (2013). Second, a common (and unquestioned) idea shapes most of these works: the changes brought by digitization have reshaped the whole organization of music production - in a "positive" (by allowing the emergence of new artists) or a "negative" way (by reinforcing the previous inequalities and monopolies). Indeed, by focusing on the more visible actors of the musical production network and by fostering a firm-based approach, most research pays more attention to the evolution implied by digitization than on the stability of the job market structure. In this article, we aim to deal with these two issues.

\subsection{Analyzing digitization implications among "ordinary" musicians: the social conditions of "appropriabil- ity"}

The few works focusing on how digitization impacted musicians' incomes and musicians' ways of working have mostly pointed out the new opportunities that these changes represented for many of the little-known musicians. For instance, Hracs (2012) asserts that digitization has been an opportunity for musicians to free themselves from the major companies and create their own music when and where they wished. Well-known studies on cultural production have indeed shown that, at a macro and micro level, "environmental turbulence leads to the emergence of entrepreneurship" in the music industry (Peterson \& Berger, 1971, p. 104). Thus, one may think that the "MP3 crisis" led to assume the responsibility "to perform a wider variety of tasks" (Hracs, 2012, p. 458) - especially all the "entrepreneurial tasks" (promotion, booking concerts and tours, etc.) that were, to date, handled by major companies. In this way, technology would have partially contributed to "lowering entry barriers and redistribut- 
ing power" (Hracs, 2012, p. 456). Some studies on musicians' work in the era of digitization are more nuanced. For instance, Jouvenet (2007) points out the considerable number of responsibilities placed on musicians' shoulders within the new organizational context of the music business. Due to the decentralization of music industries, musicians must develop skills in several domains (creative, technical, managerial) given that major companies are more reluctant to invest in the development of emerging "talents." Thus, digitization would have increased individuation and freedom in terms of professional practices for newcomers. But it has also put musicians in a more precarious economic position than before, perhaps even compromising in many cases their career prospects. Other recent works show that the "entrepreneurial" turn of the music business has been largely overemphasized by politicians and the media as an ideological ideal, "highlight[ing] positive associations of autonomy and creativity as a mask for lack of infrastructural support, uncertainty and continuous job insecurity" (Haynes \& Marshall, 2018 , p. 482). A socio-historical perspective shows that, for a long time, "autonomous and entrepreneurial modes have come to define popular musicians' patterns of working" (Stahl, 2013, p. 9). And many works did underline that, for most of the musicians, digitization did not meaningfully change their ways of working (Park, 2007; David, 2010; Cornfield, 2015).

Although useful, all of the foregoing works are limited by the restrictive definition of what it means to "be a musician." Indeed, these studies focus mainly - if not only - on musicians involved in "creation" processes, but "ordinary musicians" profiles are more diverse than these studies suggest. Comparisons between several countries reveal that, in most contemporary capitalist societies, three main professional profiles generally emerge among little-known musicians (Perrenoud \& Bataille, 2017a; Webster, Brennan, Behr, Cloonan, \& Ansell, 2018): the "artists," who earn a significant part of their incomes by playing and selling their own compositions; the "teachers," who mostly earn money through educational activities; and the "craftsmen," who mostly make a living by providing "functional" music (Umney, 2017) for weddings, corporate events, etc. In summary, the group of "ordinary musicians" has a bi-polarized structure (Perrenoud \& Bataille, 2017a): at one end of the spectrum is a "creative" pole, where musicians mainly live and define themselves as "artists"; at the other end of this spectrum, we find the alienated pole, where "functional musicians" (Umney, 2017) play music composed by others (covers) and do so "on demand". The "teachers" are located in the middle of these two extremes, and seem to be more or less integrated into the performers' network regarding the national context (Perrenoud \& Bataille, 2017a).

Furthermore, according to gender, age, social and educational background, the chances of pursuing a career as an "artist," a "teacher," or a "craftsman" are unequal. Relatively young, well-educated men are more likely to embrace an "artistic" musician profile, whereas men with low educational backgrounds are likelier to become "craftsmen" musicians (Perrenoud \& Bataille, 2017a). Women tend to be excluded from the "purely creative" pole because gender relations and representations often lead women to be eliminated from artistic consecration processes (Buscatto, 2017). Women are also generally excluded from the "craftsmen" pole because the mastering of technical skills required to be a good "sideman" is more easily attributed to and recognized as the province of men (Perrenoud, 2011). Thus, women tend to be more represented in the middle of these two extremes - i.e. among "teachers" and musicians who combine diverse revenue sources, as if the two major social figures of the "musician" were preempted by two models of masculinity: the inspired creator and the craftsman worker.

Starting from this broader definition of what it means to be an "ordinary musician" may prompt a consideration of the extent to which every segment of this professional subspace has been impacted by digitization. Indeed, some of the rare studies that covered a larger rank of musicians' profiles show that the discourses and concrete effects of the so-called "MP3 crisis" are really diverse - and somehow opposite, between the ones who earn money mainly by playing gigs and those who are more focused on the creation of new songs and records (Bacache, Bourreau, \& Moreau, 2012; Strachan 2013). This also begs the question of whether digitization deeply modified this partition by offering people from the more alienated and heteronomous pole - the "craftsmen" one - more opportunities to create, record, and sell their own music.

Here, the concept of "appropriability regime" - developed by Teece (1986) to analyze technological innovations conditions of dissemination - is very helpful to better frame our analysis. In the same time, our case analysis (addressing the circulation of symbolic/cultural goods) also underlines some of the blind spots of this classical micro-economy concept. According to Teece, the "regime of appropriability refers to the environmental factors, excluding firm and market structure, that govern an innovator's ability to capture the profits generated by an innovation" (p. 287). For Teece, two dimensions are fundamental to analyze such a regime (p. 287): "the nature" of the innovation (is 
it a new process, a new kind of product, etc.) and the "efficacy of legal mechanisms of protection" (copyright, etc.). He also mentions the impact of "complementary assets" that may help to facilitate the dissemination of innovations on the markets (a safe and robust distribution infrastructure, the development of complementary technologies...).

Teece's conceptualization of the innovation's spreading and marketization process focuses on the production and the product. It pays little attention to the individuals who are involved in such processes. This limitation is particularly problematic when innovation is embedded in the "market of symbolic goods", where the "symbolic capital" of producers and consumers, and its "accumulation and gestation" are part of the value creation process (Bourdieu, 1985, p.13). For instance, some recent works on music digitization (Mol \& Askin, 2018) show that, despite the fact digitization jeopardized the classical chain of value production in the music industry, the framing of the symbolic dimension of the final product - and especially the certification of its "authenticity" (i.e. being "true to self" and/or "true to style" (p. 193)) - is more than ever "a key" for success in the music creation market. At a time when institutional actors that were traditionally in charge of "the practice[s] of authentication features" (label, managers... ) declined, it may be that knowing the implicit "rules" of the "symbolic goods circulation" (Bourdieu, 1985, p.17) is a more crucial asset than ever for keeping a foot in the music creation market. With the democratization of the technological skills due to digitization, mastering the cultural and symbolic issues at an individual level may indeed become more and more a main condition to be recognized (and to recognize oneself) as a musician who has "something to say" (Poliak, 2002, p.12) and to stand for as a creator.

Indeed, recent research on the impact of music digitization and the increasing availability of music via platforms like Spotify or iTunes on listener tastes and music consumption show that new technologies enhance differences among listeners, according to their cultural capital - and particularly the formal educational capital as the highest degree (Leguina, Arancibia-Carvajal, $\&$ Widdop, 2017). The authors point out that "the digital divide effectively reinforces musical distinctions [that] will increasingly become polarized, as individuals without access to technologies (possession and being capable to use them adequately) become increasingly marginalized" (p. 260). Studies more focused on the top of the musical hierarchy also point out that digitization did not fundamentally change power relationships in favor of traditionally underrepresented popula- tions (e.g., women) among successful artists (Strachan, 2014).

By analyzing how the impact of digitization on ordinary musicians' revenues varies according to some of their individual characteristics (cultural capital, gender), we will thus investigate the social and symbolic dimension of the "appropriability" process, when technological innovation comes to symbolic goods.

So, what social characteristics increase or reduce the impact of digitization on the "ordinary musicians" careers? Looking at prior works on musical income and digitization, our two main hypotheses are:

$\mathrm{H} 1$ : The impact of digitization on the ways most "ordinary musicians" make money with music is marginal;

H2: Digitization only impacts musicians with significant cultural capital, notably a higher education diploma.

\section{Data and analytical strategy}

\subsection{Musicians' LIVES: a survey on con- temporary "ordinary" Swiss musi- cians}

We use longitudinal data collected from a sample of musicians in the French-speaking part of Switzerland in the early 2010's during the Musicians' LIVES project.

For some context, Switzerland is a relatively small country that relies on a specific framework to support and organize the living arts professional sector (Perrenoud \& Bataille, 2017a). Nevertheless, the contemporary evolution of music production and selling in Switzerland looks like most western countries. As shown in Figure 1, record sales, by year, have been collapsing since 2000, decreasing by a factor of four over the last 20 years.

Changes have been such that, as in many other countries, Swiss institutions that are traditionally involved in the diffusion of musical goods - such as records stores but also libraries - now confront major difficulties and have been pushed to significantly reshape the services they offer (Odoni, 2017).

As in many other countries, official data on littleknown Swiss creative workers are poor or simply missing. The only solution to the problem of obtaining quality information on these lower positions of the professional pyramid has been to gather an ad hoc data set.

Our target population consists of active musicians in the French-speaking part of Switzerland in 2013. We sampled this population using "Respondent Driven Sampling" methodology. Since its creation in the late 1990s (Heckathorn, 1997), this kind of sampling frame 


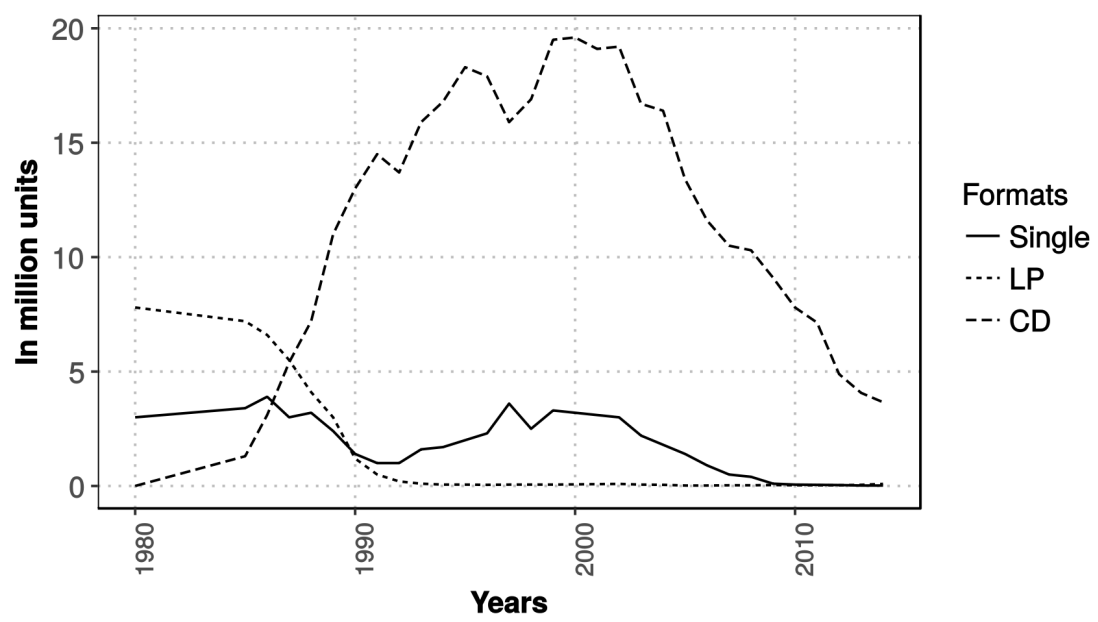

Figure 1: Record sales in Switzerland (1980-2014)

Source: IFPI Switzerland, 2019.

Note: In 2000, 19.6 millions of CD where sale in Switzerland. Fifteen years after (in 2015), the sales has been divided by five.

has been widely used to survey "hidden populations," such as sex workers, men who have sex with men, drug users, refugees (White et al., 2015) or musicians (Heckathorn \& Jeffri, 2001). It involves recruiting a few key people from the target population (called "seeds"), asking them to recruit two or three new people of their acquaintance and who are part of the target population to complete the survey, and requesting each new recruit to do the same thing. By multiplying waves of recruitment and involving each respondent in the recruitment process, it is possible to obtain a reasonably representative sample of the whole target population.

Despite high sensitivity in some specific contexts (Gile, Johnston, \& Salganik, 2015), it is now well established that such a frame can be used to recruit good quality samples (Léon, Jarlais, Jauffret-Roustide, \& Strat, 2016; Bataille, Perrenoud \& Bràondle, 2018). Starting with seven "seeds" as diverse as possible (i.e., from the classical and jazz pianists who often play in international festivals to the country and western singers who mainly sing in malls and village fairs), we recruited 123 active musicians in 2013. Generally, for a population as small and densely connected as ours, three or four waves are enough to reach "equilibrium" - i.e. the state of the process where recruitment becomes almost randomized. We reached eight waves before we decided to stop the sampling process.

All 123 musicians were surveyed with a life calendar, which gathered information on their training, their professional career (musical and non-musical) and on some other aspects of their lives (couple formation, childbirth, etc.). With these life-calendar data, we obtained retrospective information on their musical activities (with whom they played, what kind of repertoire, how often, etc.), their paramusical activities (teaching, technical jobs) and the income composition for each year of their career, from the first gig to 2013. Some of these calendars weren't fully exploitable. Thus, our final sample size is $N=106$. To map the different kinds of musical income sources, we used the typology established by the Future of Music Coalition in their analysis of US musicians' "revenue streams" (Thomson, 2013). This typology is based on eight income categories: royalties; wages (for permanent employment in an orchestra or as a part-time choirmaster once a week); gigs (public performances in a non-permanent position); income from record sales (physical or digital); studio sessions; merchandising; teaching; and others.

We thus asked each musician we surveyed to document the approximate balance among these several kinds of income during each period of their careers (including declared and undeclared income). To analyze how digitization impacted these "revenue streams," we decided to focus exclusively on the variation, over the years, of the revenues coming from royalties and record sales only. We called this subgroup of revenue at the core of our analyses the "creative" incomes. 


\subsection{Drawing the social space of musical careers: a multidimensional scaling approach to sequence analysis}

Among available statistical tools, the sequence analysis (SA) methodology (Abbott \& Hrycak, 1990) is especially well-suited to capturing and comparing the temporal dynamics of individual life courses. Our idea is to use SA tools to identify typical "creative income" sequences to (1) determine whether there have been significant changes after 2000 and the digitization of musical production and, if so, (2) shed light on the social profile of those musicians who seem to have been affected by these changes (in terms of gender, age, or educational background).

Figure 2 presents a random sample of ten of the musicians we surveyed, focusing on data about "creative incomes" within their total musical revenue. We used four categories to make note of individuals' sequences. Previous analyses of this data set (Perrenoud \& Bataille, 2017b) revealed that, for musicians who had the most "creative" profile, royalties and record sales represented, on average, $20 \%$ of their musical revenues. Our categorization of the annual musical income in four types - no creative incomes ("0\%"), creative incomes between 1 and 10 percent of the musical incomes ("1_10\%"), between 11 and 20 percent ("11_20\%"), and more than $20 \%$ (">20\%") - is based on this finding.

On every sequence plot, we drew a dashed line that corresponds to the year 2000 to better visualize any changes occurring since the beginning of the new millennium. Each individual career sequence is presented horizontally. For instance (Fig. 2), individual 1 (Indiv. 1) began his musical career in 1964, and throughout his entire career, he never earned a significant income from a "creative" source. Individual 2 (Indiv. 2) began his musical career in 2003. The year after his first gig, he earned no income from a "creative" source. Nevertheless, since 2004, royalties and record sales have represented $20 \%$ or more of his musical revenues.

Traditionally, SA follows a two-stage process (MacIndoe \& Abbott, 2006): (1) computing dissimilarities between sequences to obtain a "dissimilarity matrix" and (2) seeking the main types of patterns that "summarize" the whole set of sequences on the basis of these dissimilarity measures.

In most studies that mobilize SA in social sciences, the algorithm used to compute distances between sequences is Optimal Matching $(\mathrm{OM})^{2}$. The dissimilarity

\footnotetext{
${ }^{2}$ For all the statistical work on our sequences, we used the TraMineR package of the $\mathrm{R}$ statistical software (Gabadinho, Ritschard, Mueller, \& Studer, 2011).
}

matrix obtained through OM is based on the minimum number of basic operations (replacement, insertion, or deletion) that "transform one sequence in one other" (MacIndoe \& Abbott, 2006, p. 388). One can refine the analysis by attributing different costs to each of these operations. Using the $\mathrm{OM}$ algorithm, we attributed the same cost to each operation, as we had no sociological reasons to distinguish one operation from another. Since the surveyed musicians' careers had different lengths, we normalized the distances computed using the procedure presented by Abbott and Hrycak (1990).

Once the dissimilarity matrix is obtained, a cluster analysis is the most common process used to detect the "types" of sequences. For sociologists interested in the analysis of the social forces that inform the generation of the sequences, the "cluster" approach is particularly appealing. Indeed, once the clusters are properly identified, it is easy to compare the "cluster membership" variable with other variables of interest (gender, social background, educational attainment, etc.). This provides an overview of the social composition of each cluster and allows to formulate hypotheses on the over/under representation of the different kinds of sociological profiles with regard to the types of sequence patterns. This analytical strategy is the most common in social sciences SA literature, especially in the few cases in which SA has been applied to the analysis of artistic careers (Accominotti, 2009; Collas, 2016; Dubois \& Franà§ois, 2013; Giuffre, 1999). Nevertheless, such an approach faces strong logical and statistical limitations. As Studer et al. (2011) noted, the cluster approach can cause a misinterpretation of the results. First, the number of clusters analyzed is necessarily arbitrary, and it depends mostly on the kind of measure used to compute the partition's "goodness of fit." Second, using cluster membership as an independent variable leads to an underestimation of the internal discrepancy within each cluster. Piccaretta and Lior (2010) pointed out another crucial limitation of this cluster approach from a SA perspective: once the partition is well established, how can one assess the dissimilarities between each cluster? To better take into account the dissimilarities between groups of sequences, the authors propose an approach based on multidimensional scaling (MDS). MDS is a classic factorial technique that provides tools for analyzing a distance matrix. Using MDS in SA leads to "project" sequences" in a low dimension factorial space in such a way that the distance between cases in this space resembles as much as possible the original dissimilarity between them" (Piccarreta \& Lior, 2010, p. 166). Then "MDS maps" can be built by using the two or 


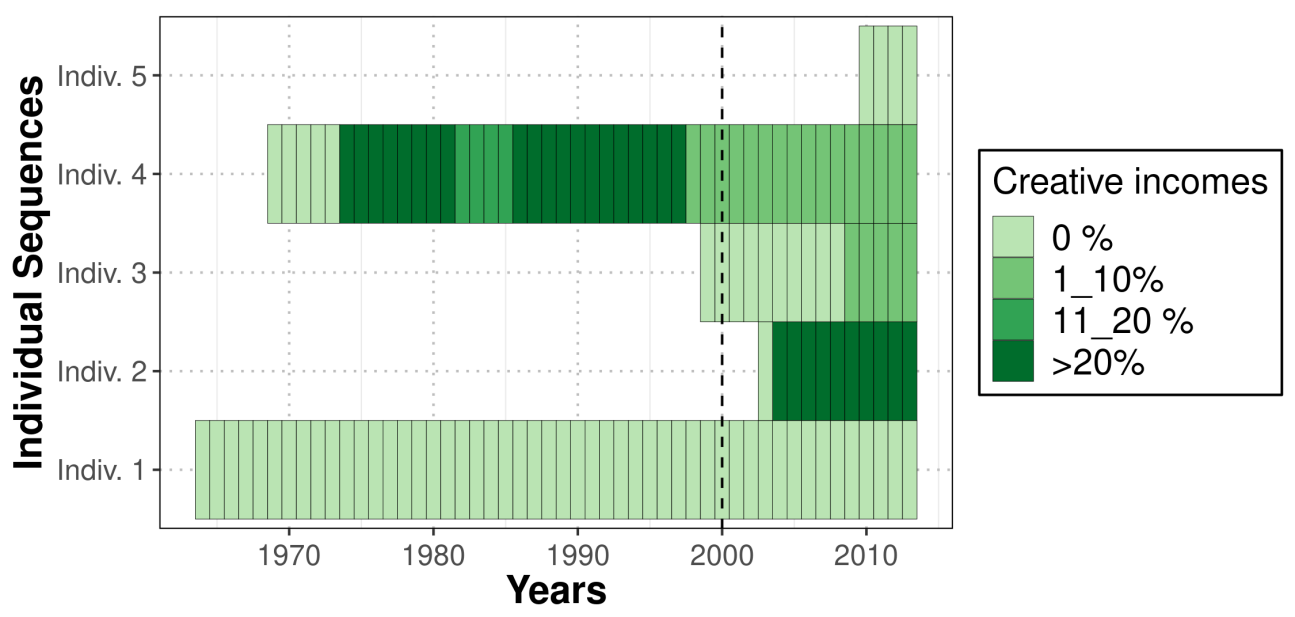

Figure 2: Random sample of ten career sequences with regard to musical income composition

Source: Musicians LIVES.

Note: The $\mathrm{x}$ axis represents time in years. The individual 5 (Indiv. 5) never earned money from a "creative income" during his short musical career (2010-2013).

three most significant dimensions (with regard to their contribution to global variance) detected by the MDS algorithm, as in other kinds of factorial analysis. This allows a "visualization of the dispersion of sequences and 'analyzing' the dissimilarity matrix without necessarily grouping cases" contrary to the cluster analysis (idem).

The MDS maps have the same properties as factorial plans. They can be used to project clouds and subcoulds of individuals. We thus used some classical tools related to geometric data analysis (Le Roux \& Rouanet, 2004) - especially statistical ellipses - to describe the sub-clouds of individuals with regard to our additional variables of interest. By doing so, we were able to analyze to what extent the trends (in terms of distance/proximity between sequences) reflected the distance/proximity among individuals according to several categorical variables. Crossing the sequences' dissimilarities and the attraction/repulsion of social individual properties may thus lead us to draw what we called the "social space" of the Swiss musicians' careers, in reference to Bourdieu's work (Bourdieu, 1992).

We used three additional variables to analyze this "social space": gender (two modalities - "Women"/ "Men"); date of birth (two modalities - "Before 1980" / "After 1980," which means being either more or less than 20 years old in 2000); and educational background (three modalities - "No diploma or vocational education" / "General secondary training" / "Tertiary training"). Educational background constitutes our "cul- tural capital" indicator. Even if the link between educational attainment and other forms of cultural capital (objectified or embodied) is weaker today than before, it remains a precious indicator to analyze new and old forms of cultural distinction (Coulageon \& Lemel, 2007).

In Table 1, we see our sample was mainly composed of men $(77.4 \%)$, of people who had a tertiary degree $(55.7 \%)$, and of people who were born before 1980 $(73.6 \%)$. These few remarks confirm that women tend to be excluded from musicians' professional groups -, as much research on popular music musicians has already pointed out (Buscatto, 2007; Reddington, 2016). Like many artistic professional groups, musicians tend to be more educated than other workers: in 2013, only $36 \%$ of the Swiss workforce had a tertiary diploma (OFS, 2014). We will now show how digitization improved access to musical creation for two relatively marginalized populations of musicians (women and people with lower educational backgrounds).

As with any other factorial technique, the choice of relevant dimensions is the first step in the MDS analysis. We used the Kruskal measure of "stress" (Kruskal, 1964) to determine the chosen model's goodness of fit. With a three-dimensional model, Kruskal's test indicated a 0.1 level of stres ${ }^{3}$ which corresponded to a "fair" goodness of fit (Kruskal, 1964). Therefore, we limited our model to only three dimensions. We nevertheless focused only on the first two dimensions, which

\footnotetext{
${ }^{3}$ See appendix.
} 


\begin{tabular}{|c|c|c|c|}
\hline Variables & Modalities & $\mathrm{N}$ & $\%$ \\
\hline \multirow[t]{2}{*}{ Sex } & Women & 24 & 22.6 \\
\hline & Men & 82 & 77.4 \\
\hline \multirow[t]{3}{*}{ Education } & Any/Vocationnal & 23 & 21.7 \\
\hline & Secondary training (gen.) & 20 & 18.9 \\
\hline & Tertiary training & 59 & 55.7 \\
\hline \multirow[t]{3}{*}{ Birth } & After 1980 & 28 & 26.4 \\
\hline & Before 1980 & 78 & 73.6 \\
\hline & Total & 106 & 100 \\
\hline
\end{tabular}

Figure 3: Supplementary variables

Source: Musicians LIVES.

Note: $22.8 \%$ of our respondents were women.

contributed the most to the global structure of the career space.

\section{Results}

\subsection{The social space of musicians' ca- reers seen through "creative" incomes: a bidimensional space}

Fig. 4a represents two individual sequence plots ordered according to the first and second MDS dimension coordinates. On these MDS sequence plots, the more the sequences differ with regard to their coordinates on the two main MDS dimensions, the more they are respectively situated at one of the two extremes of the $\mathrm{x}$-axis. Since we are looking to see whether there was a major turning point after 2000 in musical income, we also plotted the "turbulence" degree of our sequences (Fig. 4b) - i.e. the internal complexity of the sequence - with regard to the MDS coordinates of these first two dimensions. We computed this turbulence using Elzinga's algorithm (Elzinga \& Liefbroer, 2007). For the $\mathrm{x}$-axis of these "turbulence plots", we used the individual coordinates of the two main dimensions of our MDS analysis.

The two MDS sequence plots (Fig. 4a) point out the main oppositions that polarize the musicians' careers relative to their "creative" musical incomes. The first dimension (Dim 1) - which is the more important - opposes musicians who did not earn any money from royalties or record sales throughout their careers with musicians who earned "creative" revenues during more or less extended sub-sequences of their ca- reers. This first opposition seems relatively stable and unaffected by the digitization transition. No visible changes have appeared since 2000. This first individual sequence plot also points out a crucial information: for the many people who earned no money from an artistic source throughout the first ten years of their careers, their chances of embracing a "creative" career (and earning royalties) later are low. These initial results indicate that digitization did not significantly impact the careers and incomes of "ordinary musicians" since we observed a strong and durable polarization between the "creative" musicians and the others before and after 2000. This first result challenges many works that analyze the evolution of artists' careers and focus on the "peak" of creativity/consecration in the lives of people who gravitate around artistic institutions (Accominoti, 2009). By taking into account more diversified professional profiles, as we do, the most pertinent issue about artists' careers seems to be how people embrace (or do not embrace) a "creative" pattern. The "creative peak" issue seems secondary in our results.

Nevertheless, two opposite types of "creative" profiles emerged on the second dimension (Fig. 4a, Dim $2)$. At the right of the second plot, we see musicians who consistently earned a small amount of their musical incomes from a "creative" source (between 1 and $10 \%$ ), often after earning no "creative" income during the beginning of their career. At the left, we see the people who earned more than $10 \%$ or even more than $20 \%$ of their musical incomes from an artistic source for relatively long periods of their careers. We will call the individuals located at the right end of the second dimension the "part-time artists." We will call the ones located at the left end the "full-time artists." 
(a)

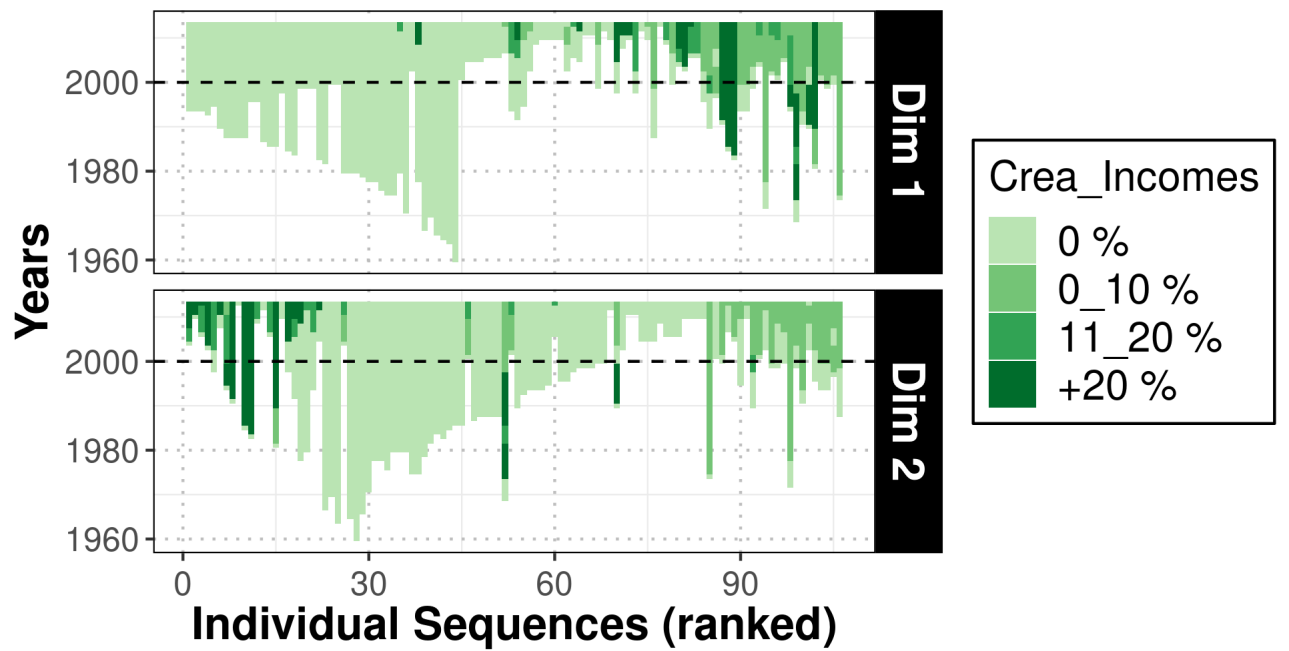

(b)

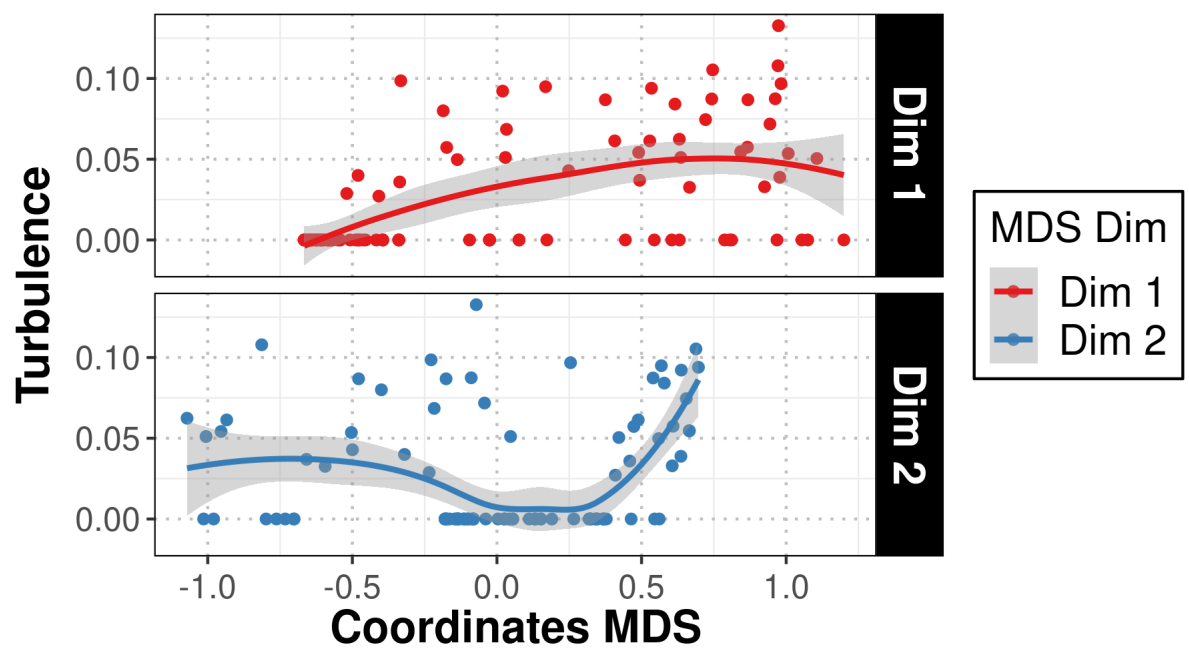

Figure 4: MDS sequence plot and turbulence plot

Source: Musicians LIVES.

Note: In Figure 4a, the individual sequences are plotted according to the rank of their coordinates on the first (Dim 1) and second (Dim 2) dimensions of the MDS analysis. In Figure 4b, the y-axis represents Elzinga's turbulence score, and the $\mathrm{x}$-axis represents the coordinate of each sequence on the first two dimensions of the MDS analysis. A regression line (Loess) with a confidence interval of $90 \%$ has been added to these last two plots. 
The income sequences affiliated with the "part-time artist" profiles tend to follow a two-stage pattern: they earned no money from "creative" sources at the beginning of their careers and then started to earn a small amount of revenue from their original music compositions. The turbulence plots (Fig. 4b) show that turbulence is significantly higher among sequences at the left end of the second dimension. The linear regression based on the turbulence score of each sequence indicates that, with a confidence interval of $90 \%$ (the gray area), the sequences located at the "part-time" artist pole are more often composite than those located at the other end. This result suggests that the two-stage pattern is a more distinctive trait of the sequences located at this pole than the ones located at the "full-time artist" pole or those in the middle.

In most of the studied sequences, the second stage of the pattern occurred around 2000 or shortly thereafter. The few (but substantial) re-orientations of the careers located at the "part-time artist" pole were probably propelled by the metamorphosis of the socioeconomic context of this period - and especially changes due to digitization. Therefore, it seems that the individuals located at this pole were musicians for whom digitization provided new opportunities of creation and diffusion of their music.

In summary, we observed two major oppositions between musicians' careers with regard to the evolution of "creative" incomes: a first opposition between those who earn money through creative activities and those who do not; and a second one between the "full-time artists" and the "part-time artists."

\subsection{Taking advantage of digitization: the impact of gender and educa- tional background}

To better understand the approach we followed in this last subsection, some basic reading keys are needed. Figure 5 represents a MDS map using the individual coordinates on the first two dimensions given by our MDS algorithm on creative income sequence dissimilarities. Along the x-axis (Dim 1) and y-axis (Dim 2 ), we present two MDS sequence plots relative to these two dimensions (creative vs. non-creative musicians; "full-time" vs."part-time" artists) to interpret the axes. In these two marginal plots, individual sequences are plotted with regard to the individual coordinates of the corresponding dimension. When individuals shared the same coordinate, we plotted the medoà $^{-} \mathrm{d}$ sequence. This medoà ${ }^{-} \mathrm{d}$ sequence was computed using the Fasang and Liao (2014) technique.

As an example of how to read Figure 5, we col- ored one random point red and drew two dotted red lines to indicate the position of the income sequence (in the marginal plot) that corresponds to this individual on the $\mathrm{x}$ - and $\mathrm{y}$-axes. We can thus see that this red individual had a relatively "turbulent" career - his income sequence is a mash-up of states. He started playing music in the 1970s and earned no "creative" income during his early years (very light green). Then, between the late 1970s and the late 1990s, he earned significant "creative" income, which often represented $20 \%$ or more of his whole musical income (dark green). Since 2000, "creative" sources of income have only represented between 0 and $10 \%$ of his musical income (light green). The location of this individual at the right end of our map and near the x-axis illustrates his intermediary position. He is among the creative musicians but between the "full-time artist" and "part-time artist" career profiles.

More generally, one can clearly see in Figure 5 that the cloud of our surveyed musicians on the MDS map is triangle shaped. Individuals located to the left of the vertical axis and near the horizontal axis (Pole 1) are those who did not earn any money from playing/selling their music ("non-creative" musicians). Those who often earned more than $10 \%$ or more than $20 \%$ of their artistic incomes during their careers (the "full-time" artists) are located at the bottom right corner of the map (Pole 2). Those who earned a little money from their musical creations (the "part-time" artists) are located at the top right corner of the map (Pole 3).

With this map, one can visualize where individuals are located within the space of careers with regard to some of their individual properties. Figure 6 represents the sub-clouds of individuals with regard to the modalities of our three supplementary variables (age $[a]$, gender $[b]$, or education $[c]$ ). To better analyze these sub-clouds, we plotted median ellipses - i.e. the zone in which at least $50 \%$ of the individuals characterized by each of the modalities was located. The longer axis of these ellipses represents the dimensions along which the sub-cloud points are located. The shorter axis represents the internal variance of the sub-cloud.

Figure 6a shows that the musicians who were born after 1980 were more likely to be located at the top of our cloud. They were also more likely to be located on the right side than on the left. One may wonder whether there has been a generational shift in ways of earning money with music. Because our respondents who did not earn any "creative" income during their careers were mainly born before 1980, one may think that younger musicians (those who were 20 years old or younger in 2000) took advantage of the new digitized recording and diffusion tools to try to sell their own 

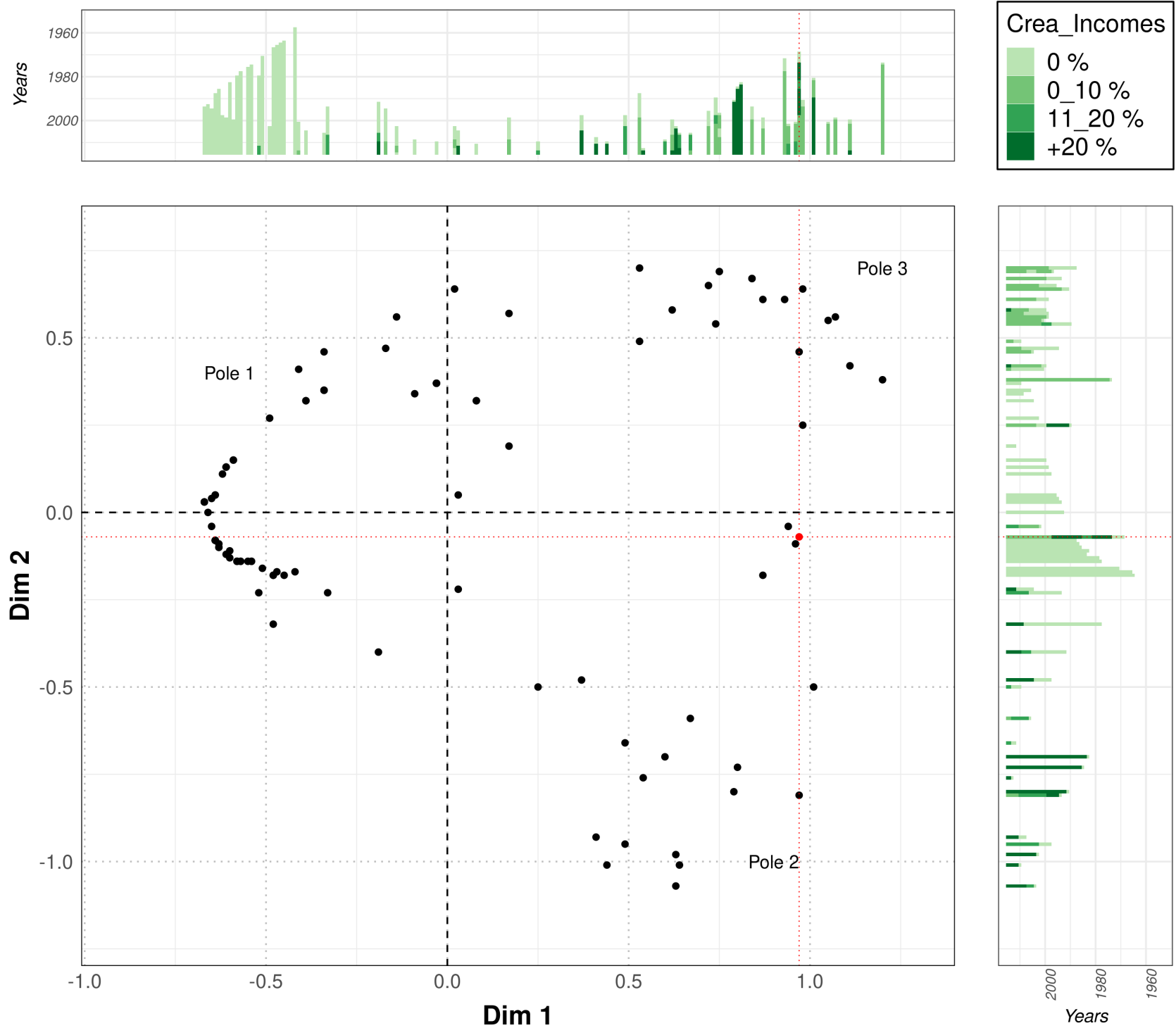

Figure 5: The musicians' career space and the cloud of individuals

Source: Musicians LIVES.

Note: The $\mathrm{x}$ axis represents the individual coordinates on the first MDS dimension (Dim 1). The y axis represents individual coordinates on the second MDS dimension (Dim 2). In the margins of this MDS map, we added two MDS sequence plots where the individual sequences are plotted, respectively, according to the individuals coordinates on Dim 1 and Dim 2. 
(a)

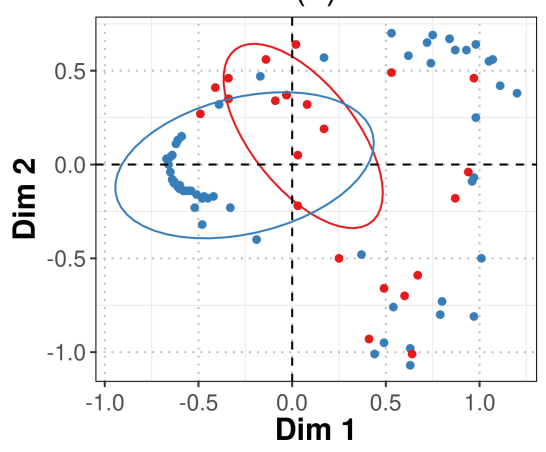

Birth $\rightarrow$ aft_1980 $\rightarrow$ bef_1980 (b)

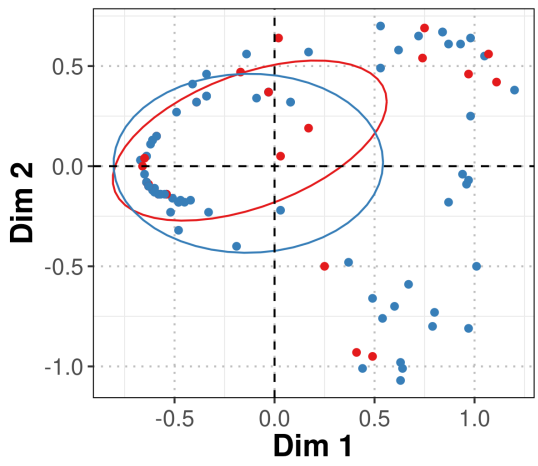

Sex $\rightarrow$ Women $\rightarrow$ Men

(c)

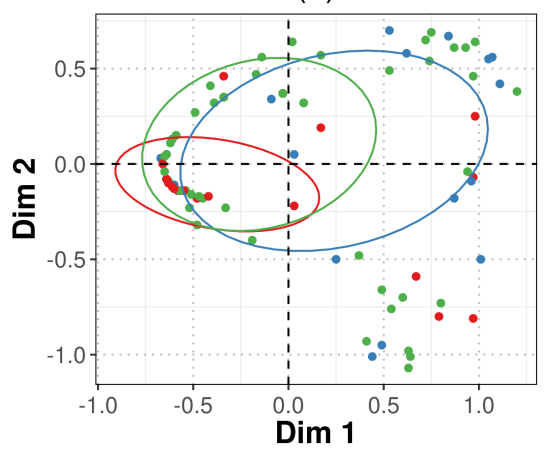

Educ $\rightarrow$ No_dip/Voc $\rightarrow$ Sec_Gen $\rightarrow$ Univ

Figure 6: The musicians' career space and the cloud of individuals

Source: Musicians LIVES.

Note: On each MDS map, points are colored according to (a) birth date, (b) sex and (c) educational attainment. The ellipses represent the zone where at least $50 \%$ of the individuals with one of the characteristics analyzed here are located. 
music.

Figure $6 \mathrm{~b}$ shows that women and men's locations tend to differ. The orientation of the men's ellipse along the horizontal axis indicates that the first dimension (which differentiates those who earn "creative incomes" and those who do not) is the only dimension that informs the internal differentiation within the group of men musicians. The left and top right orientations of the women's ellipse indicates that - when they earn "creative" incomes - women are more likely to be a part of the "part-time" creative musicians who began earning a little money from their creations thanks to the digitization process. This is consistent with our previous findings (Cf. 1.2).

Figure $6 \mathrm{c}$ shows that people with vocational training or no training at all are mostly located on the left side of the map - i.e. the pole of musicians who earn no money from their "creation." Figure 6c also shows that musicians who have secondary general training are more likely to be located at the pole of "part-time" creative musicians than those with tertiary degrees.

\section{Discussion and conclusion}

With regard to our first hypothesis, we can say that the changes provoked by digitization on ordinary musicians' incomes were very limited at this stage. This result bolsters Haynes and Marshall's (2018) argument which pointed out that the last decade's metamorphoses of the music industry had little impact on the day-to-day practices of most musicians, especially the most "ordinary" ones. We showed that, both before and after the democratization of new digital tools for recording and/or broadcasting music, the main distinction axis among the surveyed musicians opposes those who earn a musical income from their own creations and those who do not. As we wrote previously, the ordinary musicians' professional space is polarized between two major profiles: the "craftsmen" and the "artists" (Perrenoud \& Bataille, 2017a). For the "craftsmen" who mainly play "functional music," the "expression of the self," the "originality," and all the criteria through which "artistic" works are valuated are not at the core of their professional identities. In their case, being a "good musician" is mainly determined by vocational skills such as reliability, timeliness, civility with clients and employers, and everything that makes for a good service provider. Furthermore, as they usually do not work with any support staff (agents, roadies, etc.), they have to master all the administrative (prospection, contracts, etc.) and technical (gear handling, sound checks, etc.) skills necessary to perform live music. We showed that this polar- ization does not appear to have been affected by digitization. Thus it seems that digitization has not drastically improved access to "creation" for the musicians who are farthest from the artistic professional pole. The fact that musicians with the lowest cultural capital were concentrated at the "non-creative" pole reinforces this idea. In terms of musical creation, the "appropriability" of music digitization tools in order to produce one's own music seems to be shaped by the individual's cultural capital. Being seen and recognized as an artist seems to be more a matter of primary accumulation of cultural capita ${ }^{4}$ than a matter of technological changes and opportunities. For instance, most of the alumni of the "Haute Ecole de Musique" (HEMU) one of the main professional music schools in Frenchspeaking Switzerland - that we met have their own websites and/or accounts on Bandcamp, Soundcloud, etc. They use these tools to promote their own work to potential managers, journalists or simply to make their music discoverable by the widest possible audience. They often use such opportunities alongside more conventional channels (through local and national media such as TV, newspapers, magazines) which have much impact but are more competitive to reach. By contrast, one of our older interviewees - a bassist who has played as a sideman for renowned Swiss popular music singers for more than thirty years and who is an autodidact that gave up school at age 16 - declares during the interview that he is just a "manard" [a french slang word referring to a manual worker] of the musical business. Even though he has some digital skills (he runs a web page for his own communication needs), he does not consider writing and producing his own songs, because he does not "feel" like a creator and does not have "something particular" to say, as he admits.

Thus, our two hypotheses seem broadly validated. Nevertheless, our analyses show that for subgroups of traditionally marginalized musicians (especially women), digitization may have represented an opportunity to diffuse their creations and earn money from them. Such a tendency nuances our first hypothesis and needs further examination. In sociological literature, the two main factors that explain the underrepresentation of women among musicians have been well-identified: primary socialization and work interactions. Primary socialization plays a crucial role (Ravet, 2011). By choosing instruments and repertoires that will not conflict with social roles reserved for women (e.g., being modest, trying avoid embarrassing posture while playing, etc.) that keep them "in a permanent state of bod-

\footnotetext{
${ }^{4}$ And more generally any form of profitable capital besides culture but closely entangled with it, such as wealth (economic capital) and network (social capital), which haven't been discussed here.
} 
ily insecurity, or more precisely, of symbolic dependence" (Bourdieu, 2001, p. 66), the musical careers of women are from the beginning oriented toward a relatively limited range of stereotypical musical roles (singers, for instance). The second major obstacle to the durable integration of many women musicians at the core of the professional space is social interactions in the workplace (Goldin \& Rouse, 2000; Buscatto, 2007; Perrenoud, 2011; Reddington, 2012). In our case, the analyses of Swiss women musicians' experiences (Perrenoud, Bataille \& Chapuis, 2020) pointed out that their interactions with other musicians and, most importantly, with intermediaries are framed by gendered stereotypes. Many of the women musicians we interviewed underlined that a major difficulty they faced was dealing with cross-gender relations with intermediaries (manager, promoter) or with other musicians. Such relations are regularly presented as a reason of dropping out the musical career. It appears that leading their own projects by keeping control of many aspects of creation and diffusion processes of their own work is one of the best strategies for staying in the musical job market that we identified in our qualitative analyses.

Finding a way to deal with these relations appears to be a major issue that prevents people from keeping a foothold in their professional music careers (Perrenoud, Bataille \& Chapuis, 2020). Our results show that most of the women who earn money with their own creations are located among the "part-time" artistic musicians who are probably the people who did take some advantage of digitization. One may thus wonder whether digitization - which can help musicians manage all the processes of music production from recording to broadcasting - has represented an opportunity for women to bypass some intermediaries in producing their music. Nevertheless, bypassing such key actors in the professional field is a risky strategy, because these musicians earn less than $10 \%$ of their musical incomes through their own musical creations. Thus, if digitization did help women access the musical creation pole of the professional space, it may not allow them to enter the core of this sector and obtain a durable "creative" professional position. On the contrary, it seems to keep them in a relatively dominated position.

If "technology has altered the way music sounds, how it's composed and how we experience it" (Byrne, 2017, p.158), we find that digitization - even the massive and sudden changes the music industry has experienced for 30 years - rarely implies major changes for lots of ordinary musicians. If the transformations implied by such an evolution in music production obviously impact the way people sell and buy music for labels (majors or indies) and listeners (Arditi, 2014, 2018), we showed that it does not seem to bring fundamental change for most musicians for now. As for other technological innovations, highlighting the social context of "appropriability" is necessary to better understand the concrete effects and potential changes that their diffusion implies. Beyond the often prophetic predictions about the so-called "digital revolution" in music and elsewhere, the usual social relations, stratifications, and discriminations remain generally the same. 


\section{References}

Abbott, A., \& Hrycak, A. (1990). Measuring resemblance in sequence data: An optimal matching analysis of musicians' careers. American Journal of Sociology, 96(1), 144-185.

Accominotti, F. (2009). Creativity from interaction: Artistic movements and the creativity careers of modern painters. Poetics, 37(3), 267-294.

Anderson, C. (2006). The long tail: Why the future of business is selling less of more. London: Random House.

Anderson, T. J. (2013). Popular Music in a Digital Music Economy: Problems and Practices for an Emerging Service Industry. New York: Routledge.

Arditi, D. (2014). iTunes: Breaking barriers and building walls. Popular Music and Society, 37(4), 408-424.

Arditi, D. (2014). iTake-Over: The Recording Industry in the Digital Era. Lanham: Rowman \& Littlefield.

Arditi, D. (2018). Digital Subscriptions: The Unending Consumption of Music in the Digital Era. Popular Music and Society, 41(3), 302-318. https://doi.org/10.1080/03007766.2016.1264101

Askin, N., \& Mol, J. (2018). Institutionalizing Authenticity in the Digitized World of Music. In C. Jones \& M. Maoret (Eds.), Research in the Sociology of Organizations (Vol. 55, pp. 159-202). Emerald Publishing Limited. https://doi.org/10.1108/S0733-558X20180000055007.

Bacache, M., Bourreau, M., \& Moreau, F. (2012). Piracy and Creation: The Case of the Music Industry (SSRN Scholarly Paper No. ID 2000626). Rochester, NY: Social Science Research Network. Retrieved from https://papers.ssrn.com/abstract $=2000626$.

Bataille, P., Perrenoud, M., \& Brandle, K. (2018). Echantillonner les populations rares. Retour sur une expérimentation du "Respondent Driven Sampling" en milieu musical. Sociologie, 9(2), 197-214.

Behr, A., Brennan, M., \& Cloonan, M. (2016). Cultural value and cultural policy: some evidence from the world of live music. International Journal of Cultural Policy, 22(3), 403-418.

Bourdieu, P. (1985). The market of symbolic goods. Poetics, 14(1), 13-44. https://doi.org/10.1016/0304422X(85)90003-8.

Bourdieu, P. (1992). Les règles de l'art. Paris: Seuil.

Bourdieu, P. (2001). Masculine domination. Redwood: Stanford University Press.

Bourreau, M., Gensollen, M., Moreau, F., \& Waelbroeck, P. (2012). "Selling Less of More"? The Impact of Digitization on Record Companies (SSRN Scholarly Paper No. ID 2011854). Rochester, NY: Social Science Research Network. Retrieved from https://papers.ssrn.com/abstract=2011854.

Bourreau, M., Lestage, R., \& Moreau, F. (2017). E-commerce and the market structure of the recorded music industry. Applied Economics Letters, 24(9), 598-601.

Buscatto, M. (2007). Femmes du jazz: musicalités, féminités, marginalités. Paris: CNRS.

Buscatto, M. (2017). Trying to Get in, Getting in, Staying in: The Three Challenges for Women Jazz Musicians. In J. A. Halley \& D. E. Sonolet (Eds.), Bourdieu in Question: New Directions in French Sociology of Art (pp. 338-360). Leyde: Brill.

Byrne, D. (2017). How music works. Three Rivers Press.

Collas, T. (2016). Multiphase Optimal Matching: An Application to Careers of Participation in Pâtissiers' Competitions. In G. Ritschard \& M. Studer (Eds.), Proceedings of the International Con-ference on Sequence Analysis and Related Methods (pp. 571-588). Lausanne: LIVES.

Cornfield, D. B. (2015). Beyond the beat: Musicians building community in Nashville. Princeton University Press.

Coulangeon, P., \& Lemel, Y. (2007). Is 'distinction' really outdated? Questioning the meaning of the omnivorization of musical taste in contemporary France. Poetics, 35 (2), 93-111. https://doi.org/10.1016/j.poetic.2007.03.006

David, M. (2010). Peer to peer and the music industry: The criminalization of sharing. London: Sage.

Dubois, S., \& Franàßois, P. (2013). Career paths and hierarchies in the pure pole of the literary field: The case of contemporary poetry. Poetics, 41(5), 501-523.

Elzinga, C. H., \& Liefbroer, A. C. (2007). De-standardization of family-life trajectories of young adults: A cross-national comparison using sequence analysis. European Journal of Population/Revue Européenne de Démographie, 23(3-4), 225-250.

Fasang, A. E., \& Liao, T. F. (2014). Visualizing Sequences in the Social Sciences: Relative Frequency Sequence Plots. Sociological Methods \& Research, 43(4), 643-676. 
Faulkner, R., \& Becker, H. S. (2009). "Do You Know...?": The Jazz Repertoire in Action. Chicago: University of Chicago Press.

Gabadinho, A., Ritschard, G., Mueller, N. S., \& Studer, M. (2011). Analyzing and visualizing state sequences in R with TraMineR. Journal of Statistical Software, 40(4), 1-37.

Galuszka, P., \& Wyrzykowska, K. M. (2016). Running a record label when records don't sell anymore: empirical evidence from Poland. Popular Music, 35(1), 23-40. https://doi.org/10.1017/S0261143015000811

Gile, K. J., Johnston, L. G., \& Salganik, M. J. (2015). Diagnostics for respondent-driven sampling. Journal of the Royal Statistical Society: Series A (Statistics in Society), 178(1), 241-269.

Giuffre, K. (1999). Sandpiles of opportunity: success in the art world. Social Forces, 77(3), 815-832.

Goldin C., \& Rouse C. (2000). Orchestrating Impartiality: The Impact of 'Blind' Auditions on Female Musicians. The American Economic Review, 90(4), 715-741.

Guibert, G., Rebillard, F., \& Rochelandet, F. (2016). Médias, culture et numérique: Approches socioéconomiques. Paris: Armand Colin.

Haynes, J., \& Marshall, L. K. R. (2018). Reluctant entrepreneurs: musicians and entrepreneurship in the 'new' music industry. British Journal of Sociology, 69(2), 459-482. https://doi.org/10.1111/1468-4446.12286.

Heckathorn, D. D. (1997). Respondent-driven sampling: a new approach to the study of hidden populations. Social Problems, 44(2), 174-199.

Heckathorn, D. D., \& Jeffri, J. (2001). Finding the beat: Using respondent-driven sampling to study jazz musicians. Poetics, 28(4), 307-329.

Hracs, B. J. (2012). A Creative Industry in Transition: The Rise of Digitally Driven Independent Music Production. Growth and Change, 43(3), 442-461.

Hracs, B. J., \& Jansson, J. (2017). Death by streaming or vinyl revival? Exploring the spatial dynamics and value-creating strategies of independent record shops in Stockholm. Journal of Consumer Culture, online first. https://doi.org/10.1177/1469540517745703.

Jouvenet, M. (2007). La carrière des artistes et les transformations de la production musicale. Relations de travail et relation au travail dans le monde des musiques rap et électroniques. Sociologie du Travail, 49(2), $145-161$.

Klein, B., Meier, L. M., \& Powers, D. (2017). Selling Out: Musicians, Autonomy, and Compromise in the Digital Age. Popular Music and Society, 40(2), 222-238.

Kruskal, J. B. (1964). Multidimensional scaling by optimizing goodness of fit to a nonmetric hypothesis. Psychometrika, 29(1), 1-27.

Le Roux, B., \& Rouanet, H. (2004). Geometric data analysis: from correspondence analysis to structured data analysis. Dordrecht: Kluwer Academic Publisher.

Leguina, A., Arancibia-Carvajal, S., \& Widdop, P. (2017). Musical preferences and technologies: Contemporary material and symbolic distinctions criticized. Journal of Consumer Culture, 17(2), 242-264.

Léon, L., Jarlais, D. D., Jauffret-Roustide, M., \& Strat, Y. L. (2016). Update on respondent-driven sampling: Theory and practical considerations for studies of persons who inject drugs. Methodological Innovations, 9, 1-9. https://doi.org/10.1177/2059799116672878.

Leyshon, A. (2001). Time-Space (and Digital) Compression: Software Formats, Musical Networks, and the Reorganisation of the Music Industry. Environment and Planning A, 33(1), 49-77. https://doi.org/10.1068/a3360

Leyshon, A. (2009). The Software Slump?: Digital Music, the Democratisation of Technology, and the Decline of the Recording Studio Sector within the Musical Economy. Environment and Planning A, 41(6), 1309-1331. https://doi.org/10.1068/a40352

Leyshon, A., Webb, P., French, S., Thrift, N., \& Crewe, L. (2005). On the reproduction of the musical economy after the Internet. Media, Culture \& Society, 27(2), 177-209. https://doi.org/10.1177/ 0163443705050468 .

Marshall, L. (Ed.). (2013). The International Recording Industries. New York: Routledge.

MacIndoe, H., \& Abbott, A. (2006). Sequence Analysis and Optimal Matching Techniques for Social Science Data. In A. Bryman \& M. Hardy (Eds.), Handbook of Data Analysis (pp. 387-406). London: Sage.

McLeod, K. (2005). MP3s are killing home taping: The rise of Internet distribution and its challenge to the major label music monopoly. Popular Music and Society, 28(4), 521-531.

Marshall, L. (Ed.). (2013). The International Recording Industries. New York: Routledge. 
Odoni, M. (2017). «Ah c'est vous qui êtes là pour dire que le CD va mourir?»,: la souffrance des bibliothécaires au c?ur du régime numérique. SociologieS. Retrieved from http://sociologies.revues.org/6104.

OFS. (2014). L'ESPA en bref 2014. L'enquête suisse sur la population active. Neuchâtel: Office Fédérale de la Statistique.

Park, D. J. (2007). Conglomerate Rock: The Music Industry's Quest to Divide Music and Conquer Wallets. Lanham: Lexington Books.

Perrenoud, M. (2007). Les musicos. Enquête sur des musiciens ordinaires. Paris: La découverte.

Perrenoud M. (2011). Les musicos et la "masculinité", in Welzer-Lang D. \& Zaouche C. (eds.), Masculinité : état des lieux. Toulouse: Eres, 57-70.

Perrenoud, M. \& Bataille P. (2017a). Artist, Craftsman, Teacher: "Being a Musician" in France \& Switzerland. Popular Music and Society, 40(5), 592-604. https://doi.org/10.1080/03007766.2017.1348666.

Perrenoud, M. \& Bataille, P. (2017b). Etre musicien.ne interprète en Suisse romande : modalités du rapport au travail et à l'emploi. Revue suisse de sociologie, 43(2), 309-333.

Perrenoud, M., Bataille, P., \& Chapuis, J. (2020). Carrières de musiciennes en Suisse romande, une approche par les méthodes mixtes, in Octobre, S. \& Patureau F. (eds.), Sexe et genre des mondes culturels. Paris: La documentation franà§aise / DEPS, 115-130

Peterson, R. A., \& Anand, N. (2004). The Production of Culture Perspective. Annual Review of Sociology, 30(1), 311-334. https://doi.org/10.1146/annurev.soc.30.012703.110557.

Peterson, R. A., \& Berger, D. G. (1971). Entrepreneurship in Organizations: Evidence from the Popular Music Industry. Administrative Science Quarterly, 16(1), 97-106. https://doi.org/10.2307/2391293

Piccarreta, R., \& Lior, O. (2010). Exploring sequences: a graphical tool based on multi-dimensional scaling. Journal of the Royal Statistical Society: Series A (Statistics in Society), 173(1), 165-184. https://doi.org/10.1111/j.1467985X.2009.00606.x

Poliak, C. (2002). Manières profanes de "parler de soi." Genèses, 47, 4-20.

Pras, A., Guastavino, C., \& Lavoie, M. (2013). The impact of technological advances on recording studio practices. Journal of the American Society for Information Science and Technology, 64(3), 612-626. https://doi.org/10.1002/asi.22840.

Ravet, H. (2011). Musiciennes. Enquête sur les femmes et la musique. Paris: Autrement.

Stahl, M., \& Meier, L. (2012). The Firm Foundation of Organizational Flexibility: The 360 Contract in the Digitalizing Music Industry. Canadian Journal of Communication, 37(3).

Stahl, M. (2013). Unfree masters: Popular music and the politics of work. Durham: Duke University Press. Strachan, I. (2013). Digitization and Recorded Music Sales: Whither the 'Long Tail'? (SSRN Scholarly Paper No. ID 2287193). Retrieved from Social Science Research Network website: https://papers.ssrn.com/abstract=2287193

Strachan, I. (2014). Female Artists and the Digitization of Labor in the Music Industry (SSRN Scholarly Paper No. ID 2533167). Retrieved from Social Science Research Network website: https://papers.ssrn.com/abstract=2533167.

Studer, M., Ritschard, G., Gabadinho, A., \& Müller, N. S. (2011). Discrepancy analysis of state sequences. Sociological Methods \& Research, 40(3), 471-510. Press.

Taylor, T. D. (2015). Music and Capitalism: A History of the Present. Chicago: University of Chicago

Teece, D. J. (1986). Profiting from technological innovation: Implications for integration, collaboration, licensing and public policy. The Transfer and Licensing of Know-How and Intellectual Property: Understanding the Multinational Enterprise in the Modern World, 15, 67-88.

Thomson, K. (2013). Roles, Revenue, and Responsibilities: The Changing Nature of Being a Working Musician. Work and Occupations, 40(4), 514-525.

Umney, C. (2017). Moral economy, intermediaries and intensified competition in the labour market for function musicians. Work, Employment and Society, 31(5), 834-850.

Webster, E., Brennan, M., Behr, A., Cloonan, M., \& Ansell, J. (2018). Valuing live music: The UK Live Music Census 2017 report. Swindon: Arts and humanities research council.

White, R. G., Hakim, A. J., Salganik, M. J., Spiller, M. W., Johnston, L. G., Kerr, L., ... Hladik, W. (2015). Strengthening the Reporting of Observational Studies in Epidemiology for respondent-driven sampling studies: "STROBE-RDS" statement. Journal of Clinical Epidemiology, 68(12), 1463-1471. https://doi.org/10.1016/j.jclinepi.2015.04

Whiteley S. (ed.) (1997). Sexing the Groove. Popular Music and Gender, London and New York: Routledge. Williamson, J., \& Cloonan, M. (2007). Rethinking the music industry. Popular Music, 26 (2), 305-322. 
Witt, S. (2015). How music got free: The end of an industry, the turn of the century, and the patient zero of piracy. New York: Penguin. 


\section{Appendix}

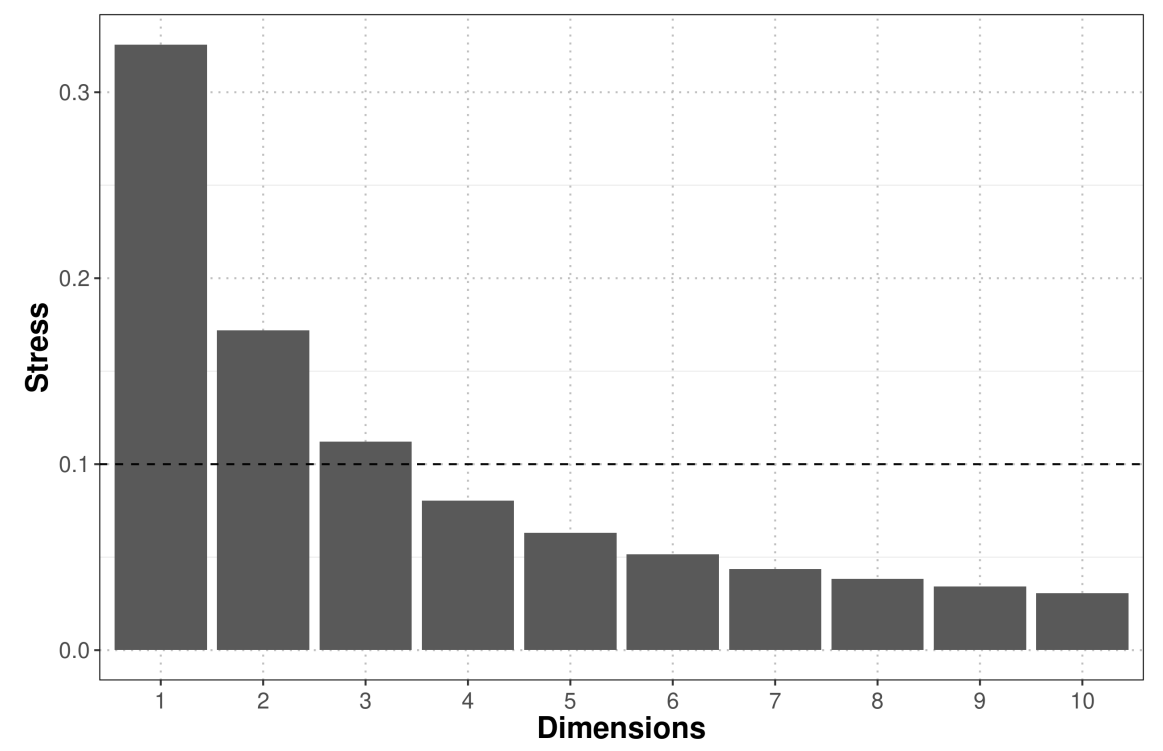

Figure 7: Level of stress and dimensions of the MDS model

Source: Musicians LIVES. 